Research Article

\title{
Cutting-Caving Ratio Optimization of Fully Mechanized Caving Mining with Large Mining Height of Extremely Thick Coal Seam
}

\author{
Kai Wang, ${ }^{1}$ Tong Zhao $\mathbb{D},{ }^{2}$ Kaan Yetilmezsoy, ${ }^{3}$ and Xiaoqiang Zhang $\mathbb{D}^{1}$ \\ ${ }^{1}$ College of Mining Technology, Taiyuan University of Technology, Taiyuan, Shanxi Province 030024, China \\ ${ }^{2}$ Key Laboratory of In situ Modified Mining Ministry of Education, Taiyuan University of Technology, Taiyuan, \\ Shanxi Province 030024, China \\ ${ }^{3}$ Department of Environmental Engineering, Faculty of Civil Engineering, Yildiz Technical University, Davutpasa Campus, \\ Esenler, Istanbul 34220, Turkey
}

Correspondence should be addressed to Tong Zhao; zhaotong3501@126.com

Received 24 July 2019; Accepted 6 September 2019; Published 7 October 2019

Academic Editor: Yinshan Tang

Copyright (c) 2019 Kai Wang et al. This is an open access article distributed under the Creative Commons Attribution License, which permits unrestricted use, distribution, and reproduction in any medium, provided the original work is properly cited.

Serious rib spalling and low recovery rate problems caused by the poor top-coal caving property (TCCP) were investigated in fully mechanized caving mining with large mining height (FMCMLMH) of extremely thick coal seam. For this aim, theoretical calculation, numerical simulation, and engineering application were applied to study the reasonable cutting-caving ratio under the influence of different factors. The calculation formula of reasonable cutting height in FMCMLMH was obtained, and effective factors were determined. Moreover, $F_{\mathrm{t}}$ (the top-coal yield failure coefficient) and $F_{\mathrm{w}}$ (the coal wall yield failure coefficient) were defined, and each factor was fitted by using a linear regression equation. The minimum $F_{\mathrm{t}}$ of fully fractured top coal was 0.6 , and the main influencing factors were buried depth and Protodyakonov coefficient. The maximum $F_{\mathrm{w}}$ of the stable coal wall was 1.5, and the main influencing factors were buried depth and cutting height. According to the relationship between coal wall stability and recovery rate, the relationship between coal seam strength and top-coal thickness at different cutting heights was obtained, and the mining zone was divided into four subzones. Engineering application showed that the optimal cutting height of Xiegou Coal Mine was $4 \mathrm{~m}$, the cutting-caving ratio was $1: 2.75$, and the recovery rate could reach more than $85 \%$, which was the most reasonable.

\section{Introduction}

With a thickness of $8-20 \mathrm{~m}$, a large number of extremely thick coal seams occur in northwestern China, which are mainly distributed in Shanxi, Ningxia, and Xinjiang mining areas $[1,2]$. Restricted by the mining height and coal wall rib spalling, the maximum mining height of fully mechanized face with great mining height (FMFGMH) is $8.8 \mathrm{~m}$ [3]. Restrained by the top-coal caving property (TCCP) and the recovery rate, the coal seam thickness in the fully mechanized mining with top-coal caving technology (FMMTCCT) is less than $14 \mathrm{~m} \mathrm{[4].} \mathrm{Considering} \mathrm{the} \mathrm{complicated} \mathrm{mining}$ technology and low recovery rate, the slice mining cannot suit the extremely thick coal seam [5-7]; thus, the fully mechanized caving mining with large mining height
(FMCMLMH) is gradually becoming the main mining technology. Utilizing ground pressure to break the top coal, the power source and the mechanical mechanism of top-coal caving and rib spalling are all the same. Enlarging the cutting height can improve the application scope of FMCMLMH as well as the TCCP but increases the rib spalling. Apparently, rib spalling prevention contradicts sharply with the improvement of TCCP. Determination of the contradictions by optimizing the cutting-caving ratio is the core of performing the FMCMLMH of extremely thick coal seams [8].

So far, many researchers have conducted in-depth studies on issues related to FMCMLMH and cutting-caving ratio optimization. For instance, Bai and Tu [9] provided a general summary of the characterizing mining-induced fractures in near-face regions to guide the longwall top-coal 
caving mining. In another study, Liang et al. [10] studied the roof-coal caving characteristics of the coal seam with complicated structure and used the deep-hole blasting technique to reduce the fragments of roof-coal crushed. Additionally, Huang et al. [11] exploited the effect of mining thickness on overburden movement and underground pressure characteristics for extra thick coal seam by sublevel caving. Moreover, Chen et al. [12] analyzed the stability control of underground roadways subjected to stresses caused by extraction of a $10-\mathrm{m}$ thick coal seam. Furthermore, Liu et al. [13] investigated the effect of strata conditions on shield pressure and surface subsidence at a longwall top-coal caving working face.

The above researches mainly focused on the mining height, the working resistance, and the coal wall stability and promoted the FMCMLMH. However, to the best of the authors' knowledge, the reasonable cutting-caving ratio of extremely thick coal seam when restricted by both coal wall stability and TCCP under different influences have rarely been studied and is needed to be solved. Thus, considering the scarcity of the literature in this field, in the present study, the theoretical calculation, numerical simulation, and engineering application were implemented to optimize the cutting-caving ratio of the FMCMLMH in extremely thick coal seam.

\section{Materials and Methods}

2.1. Geological Conditions. The studied mine is located in Lvliang City, Shanxi Province, the Xiegou Coal Mine (with latitude $38^{\circ} 32^{\prime} 40^{\prime \prime}-38^{\circ} 44^{\prime} 39^{\prime \prime}$ north and longitude $111^{\circ} 05^{\prime} 30^{\prime \prime}-111^{\circ} 08^{\prime} 33^{\prime \prime}$ east, and an elevation of $924 \mathrm{~m}$ above sea level) and has a capacity of 15 million tons/year. No. 13 is the main recoverable coal seam with dip angle $6^{\circ}-12^{\circ}$, thickness $(15.21 \pm 0.9) \mathrm{m}$, buried depth $360 \mathrm{~m}$, and compressive strength $22 \mathrm{MPa}$, which indicates the medium hard coal seam. The immediate roof is mostly sandy mudstones and mudstones, and the main roof is medium-grained sandstones (Figure 1).

\subsection{Reasonable Cutting-Caving Ratio Simulation of Extremely} Thick Coal Seam. In the present study, numerical simulations were conducted within the framework of the software FLAC $^{3 \mathrm{D}}$ (Fast Lagrangian Analysis of Continuain 3D, produced by Itasca (Wuhan) Consulting, Co., Ltd., Wuhan City, Hubei Province, China) operating on a Lenovo V470 (Intel Core i5-2410M CPU, 2.30 GHz, 2 GB of RAM, 64 bit) PC [14]. In the computational analysis, a model of FMCMLMH with $X \times Y \times Z=200 \mathrm{~m} \times 130 \mathrm{~m} \times 91.25 \mathrm{~m}$ was established, and 402154 grids and 412015 nodes were developed. The floor and the roof were $20.13 \mathrm{~m}$ and $51.12-$ $59.12 \mathrm{~m}$, respectively, and the coal thickness was $12-20 \mathrm{~m}$. The surrounding and the floor were fixed by limiting displacement and stress, and the overlying strata weight was applied on the roof [15]. After the establishment of the model, an open-off cut was made at $x=50 \mathrm{~m}$. The step interval of coal cutting was $5 \mathrm{~m}$ with the release of the top coal.
The coal body was resistant to compression but not to tensile stress. The size of the yield failure zone could be used as an important indicator to measure the top-coal damage $[16,17]$. Therefore, in the present study, the top-coal yield failure coefficient (TCYFC), $F_{\mathrm{t}}$, was defined as the ratio of the yield failure zone to the top-coal zone in the unit face width for the quantitative description of TCCP. The existence and damage degree of the yield failure zone were reported as the key factors behind the coal wall stability [18]. To quantitatively describe the coal wall damage and the stability, the coal wall yield failure coefficient (CWYFC), $F_{w}$, was defined as the ratio of the yield failure zone to the coal body zone in unit length.

A five-factor and five-level orthogonal test scheme was established by the orthogonal test method to study the effect of cutting height, coal thickness, buried depth, Protodyakonov coefficient, and supporting intensity on $F_{\mathrm{t}}$ and $F_{\mathrm{w}}$. The 25 orthogonal test schemes are presented in Table 1. Overall, the mining was divided into three stages: (i) in the first weighting stage $(0-75 \mathrm{~m})$, the top coal was released after calculations balanced with the working face (first weighting distance $=75 \mathrm{~m}$ ); (ii) in the periodic weighting stage (75$130 \mathrm{~m}$ ), the top coal was cut and released periodically; and (iii) in the end mining stage (130-150.6 m), cutting and caving were continued until the end of mining. The schematic diagram of the working face is shown in Figure 2.

2.3. Multifactor Analysis Results of TCCP. For the multifactor simulation analysis of TCCP, the TCYFC in schemes $1-25$ were $0.4251,0.6252,0.7671,0.8495,0.9397,0.8408$, $0.9540,0.9763,0.4206,0.6045,0.9819,0.3785,0.6292,0.9153$, $0.9458,0.7439,0.9180,0.9386,0.9723,0.4191,0.9408,0.9703$, $0.5004,0.6312$, and 0.9018 , respectively.

The fitting curves of each factor and the TCYFC are depicted in Figure 3. When the buried depth exceeded $400 \mathrm{~m}$, the TCCP was mostly stable, so $400 \mathrm{~m}$ can be determined as the critical value of buried depth. The relationship between the factors and yield failure coefficient of top coal $F_{\mathrm{t}}$ is approximately logarithmic, and multivariate linear regression could be performed, assuming the following multiple linear regression equation:

$$
\begin{aligned}
& F_{\mathrm{t}}=a+b X_{1}+c X_{2}+d X_{3}+e X_{4}+m X_{5}, \\
& X_{i}=\ln T_{i}, \quad i=1,2,3,4,5
\end{aligned}
$$

where $F_{\mathrm{t}}$ is the top-coal yield failure coefficient; $X_{1}, X_{2}, X_{3}$, $X_{4}$, and $X_{5}$ refer the cutting height $h$, the coal seam thickness $M$, Protodyakonov coefficient $f$, the buried depth $H$, and the supporting intensity $P$, respectively; and $a, b, c, d, e$, and $m$ are the coefficients to be determined.

Substitution of the test results into equation (1) yields the following linear regression:

$$
\begin{aligned}
F_{\mathrm{t}}= & 0.853994+0.13486 \ln h-0.14296 \ln M+0.2436 \ln f \\
& +0.0013581 \ln H+0.01546 \ln P,
\end{aligned}
$$

where $F=27.37417$ and its significance level $\left(P=4.6129 \times 10^{-8}, P \ll 0.05\right)$ indicated that there was a real 


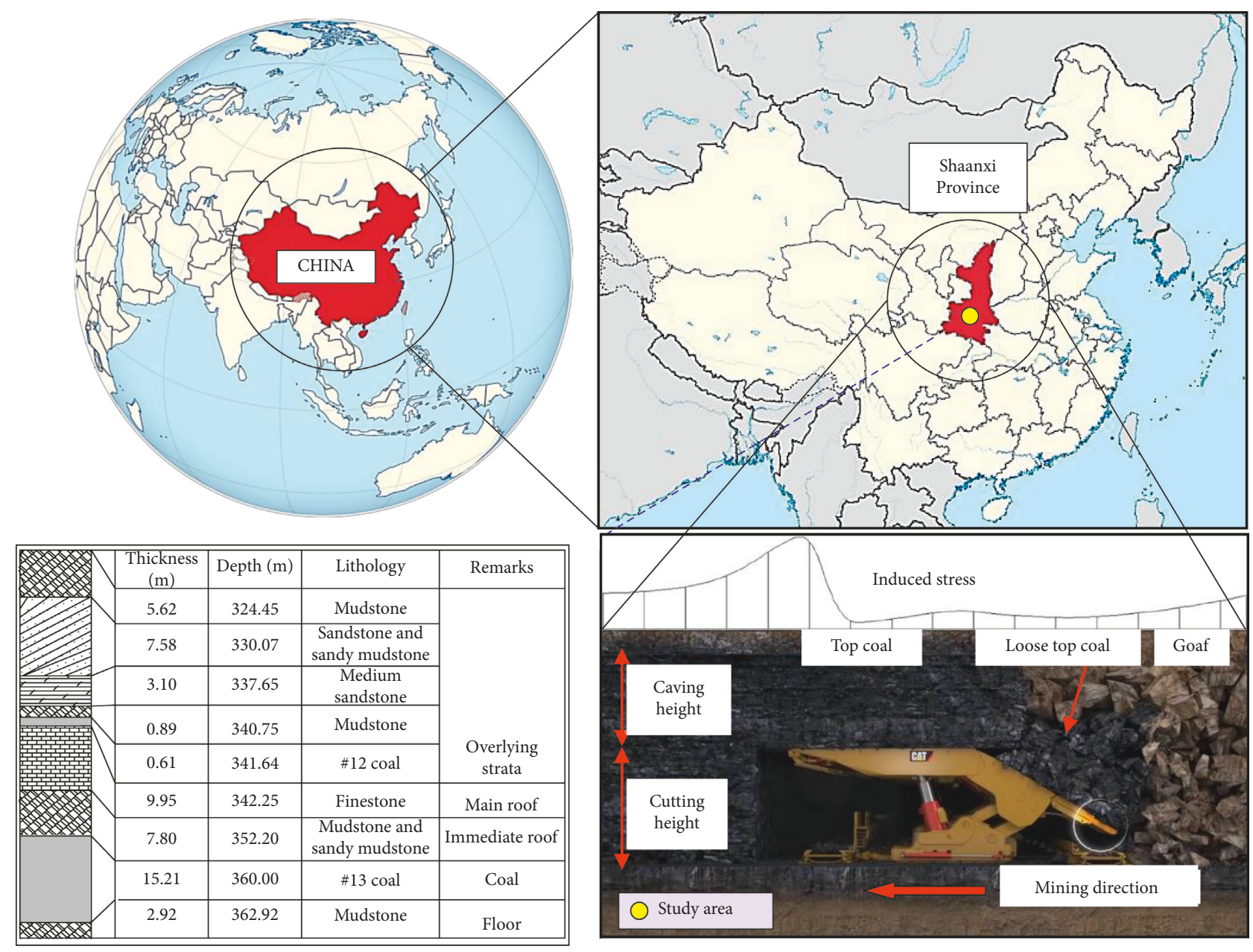

FIGURE 1: Map showing the location and outline of the studied mine and area.

(significant) five-element linear regression equation, which could be used to predict the TCCP of FMCMLMH under certain conditions.

To determine the impact significance of each factor on the top-coal damage, the extremum difference analysis was introduced considering the differences between the maximum and minimum values of the TCYFC $F_{\mathrm{t}}$ under different process parameters. The values were obtained as follows: (i) cutting height $h=0.79838-0.72132=0.07706$; (ii) coal seam thickness $M=0.7865-0.75778=0.02872$; (iii) Protodyakonov coefficient $f=0.81066-0.73264=0.07802$; (iv) buried depth $H=0.9681-0.42874=0.53936$; and (v) supporting intensity $P=0.7769-0.75066=0.02624$.

Furthermore, the impact of each factor was in the following order: buried depth $H>$ Protodyakonov coefficient $f>$ cutting height $h>$ coal seam thickness $M>$ supporting intensity $P$. The obtained results demonstrated that the buried depth and the Protodyakonov coefficient were the main factors affecting the TCYFC.

2.4. Multifactor Analysis Results of Coal Wall Stability. For the simulation analysis of the factors affecting the coal wall damage, the CWYFC of scheme 1 to 25 were 1.413 , $1.347,1.347,1.613,1.720,1.714,1.986,2.171,1.414,1.329$,
$2.530,1.380,1.440,1.830,2.070,1.622,1.956,2.322$, $2.867,1.456,2.488,3.072,1.568,1.608$, and 2.056, respectively.

The fitting curves of the factors and the CWYFC are illustrated in Figure 4. The determination coefficients $R^{2}$ were calculated as $0.9929,0.9885,0.9838,0.9370$, and 0.9857 , respectively. Thus, there was an approximate linear relationship between the CWYFC and the logarithmic form of each factor, which could be used for the multivariate linear regression.

The multiple linear regression equation can be assumed as follows:

$$
\begin{aligned}
F_{\mathrm{w}} & =A+B X_{1}+C X_{2}+D X_{3}+E X_{4}+F X_{5}, \\
X_{i} & =\ln \beta_{i}(i=1,2,3,4,5),
\end{aligned}
$$

where $F_{\mathrm{w}}$ is the coal wall yield failure coefficient; $\beta_{1}, \beta_{2}, \beta_{3}, \beta_{4}$, and $\beta_{5}$ refer the cutting height $h$, the coal seam thickness $M$, Protodyakonov coefficient $f$, the buried depth $H$, the supporting intensity $P$; and $A, B, C, D, E$, and $F$ are the coefficients to be obtained.

Substitution of the test data into equations (3) and (4) yields linear regression as follows: 
TABle 1: Orthogonal test scheme.

\begin{tabular}{|c|c|c|c|c|c|}
\hline \multirow{2}{*}{ Schedule } & \multicolumn{5}{|c|}{ Combination level } \\
\hline & Mining height $(\mathrm{m})$ & Coal thickness (m) & Protodyakonov coefficient & Buried depth (m) & Support strength $(\mathrm{MPa})$ \\
\hline 1 & 3.0 & 12 & 1.0 & 100 & 0.8 \\
\hline 2 & 3.0 & 14 & 1.5 & 200 & 1.0 \\
\hline 3 & 3.0 & 16 & 2.0 & 300 & 1.2 \\
\hline 4 & 3.0 & 18 & 2.5 & 400 & 1.4 \\
\hline 5 & 3.0 & 20 & 3.0 & 500 & 1.6 \\
\hline 6 & 3.5 & 12 & 1.5 & 300 & 1.4 \\
\hline 7 & 3.5 & 14 & 2.0 & 400 & 1.6 \\
\hline 8 & 3.5 & 16 & 2.5 & 500 & 0.8 \\
\hline 9 & 3.5 & 18 & 3.0 & 100 & 1.0 \\
\hline 10 & 3.5 & 20 & 1.0 & 200 & 1.2 \\
\hline 11 & 4.0 & 12 & 2.0 & 500 & 1.0 \\
\hline 12 & 4.0 & 14 & 2.5 & 100 & 1.2 \\
\hline 13 & 4.0 & 16 & 3.0 & 200 & 1.4 \\
\hline 14 & 4.0 & 18 & 1.0 & 300 & 1.6 \\
\hline 15 & 4.0 & 20 & 1.5 & 400 & 0.8 \\
\hline 16 & 4.5 & 12 & 2.5 & 200 & 1.6 \\
\hline 17 & 4.5 & 14 & 3.0 & 300 & 0.8 \\
\hline 18 & 4.5 & 16 & 1.0 & 400 & 1.0 \\
\hline 19 & 4.5 & 18 & 1.5 & 500 & 1.2 \\
\hline 20 & 4.5 & 20 & 2.0 & 100 & 1.4 \\
\hline 21 & 5.0 & 12 & 3.0 & 400 & 1.2 \\
\hline 22 & 5.0 & 14 & 1.0 & 500 & 1.4 \\
\hline 23 & 5.0 & 16 & 1.5 & 100 & 1.6 \\
\hline 24 & 5.0 & 18 & 2.0 & 200 & 0.8 \\
\hline 25 & 5.0 & 20 & 2.5 & 300 & 1.0 \\
\hline
\end{tabular}

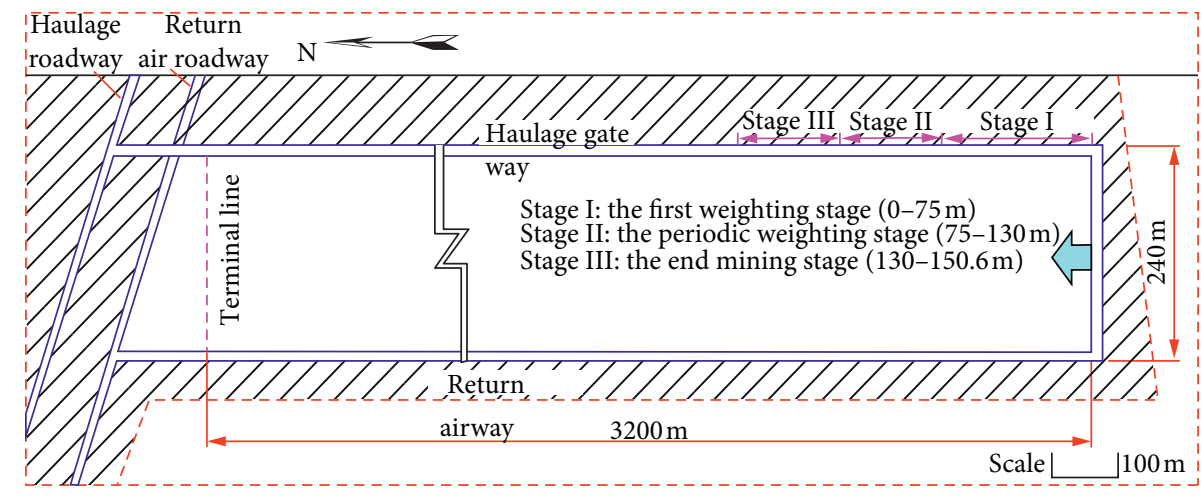

FIgURE 2: The schematic diagram of the 23103 working face.

$$
\begin{aligned}
F_{\mathrm{w}}= & 1.58574+0.26292 \ln h-0.13026 \ln M-0.326034 \ln f \\
& +0.00248 \ln H-0.1268 \ln P
\end{aligned}
$$

where $F=30.11112$ and its significance level $\left(P=1.4 \times 10^{-4}\right.$, $P \ll 0.05)$ revealed that there was a real (significant) fiveelement linear regression equation, which could be used to estimate coal wall stability of FMCMLMH under certain conditions.

According to the extremum difference analysis, the impact of each factor on the coal wall stability was determined. The obtained results were as follows: (i) cutting height $h=2.1584-1.488=0.6704$; (ii) coal seam thickness $M=1.9334-1.8962=0.0372$; (iii) Protodyakonov coefficient $f=1.9932-1.6956=0.2976$; (iv) buried depth $H=2.272-$
$1.4462=0.8258 ;$ and $(\mathrm{v})$ supporting intensity $P=1.9138-$ $1.7452=0.1686$.

The impact of each factor was in the following order: buried depth $H>$ cutting height $h>$ Protodyakonov coefficient $f>$ supporting intensity $P>$ coal seam thickness $M$. These results indicated that the buried depth and the cutting height were the main influencing factors of the CWYFC.

\section{Results and Discussion}

3.1. Study on the Coal Body Fracture Mechanism. According to the strain equivalence hypothesis of the damage constitutive equation, the basic relationship of the damage constitutive can be established as follows [19]:

$$
[\sigma]=\left[\sigma^{*}\right][I-\Omega]=[E][\varepsilon][I-\Omega],
$$




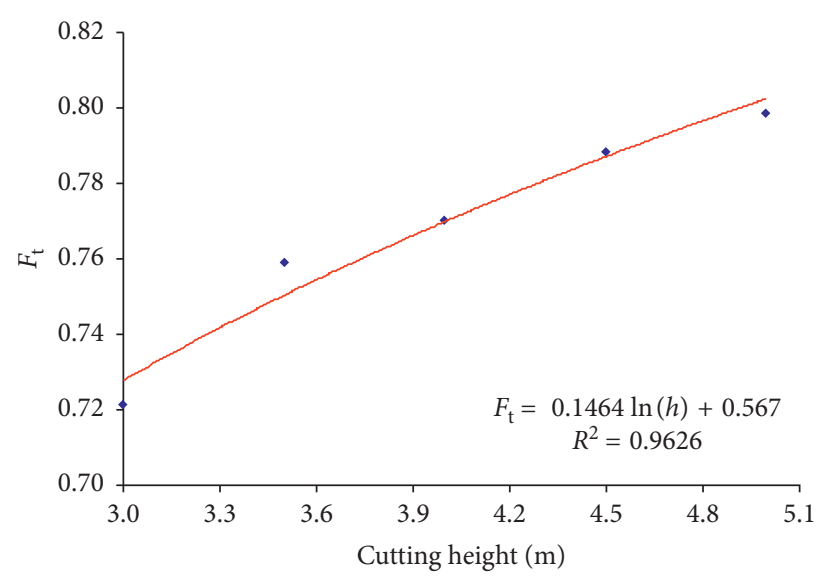

(a)

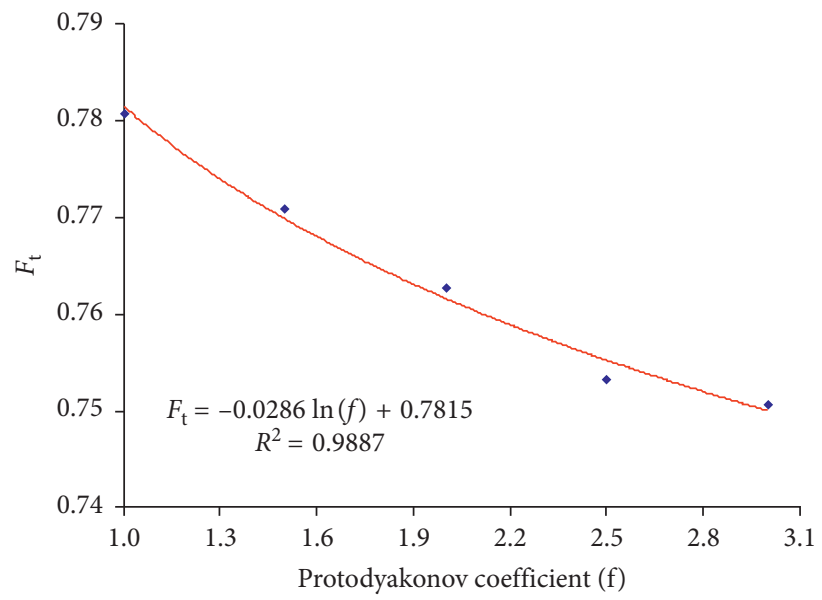

(c)

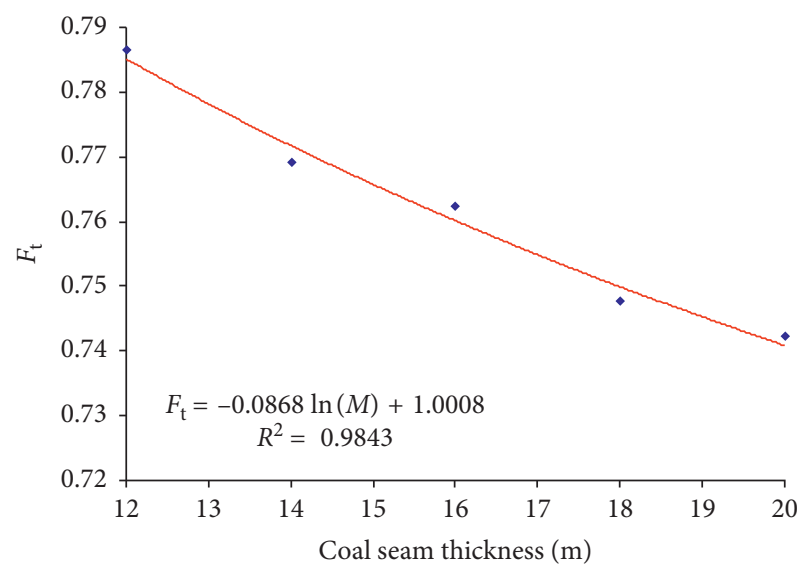

(b)

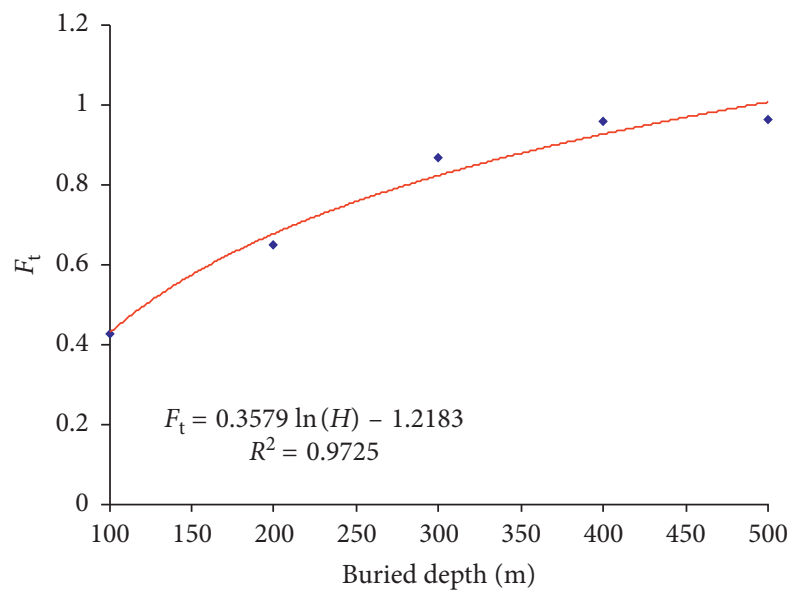

(d)

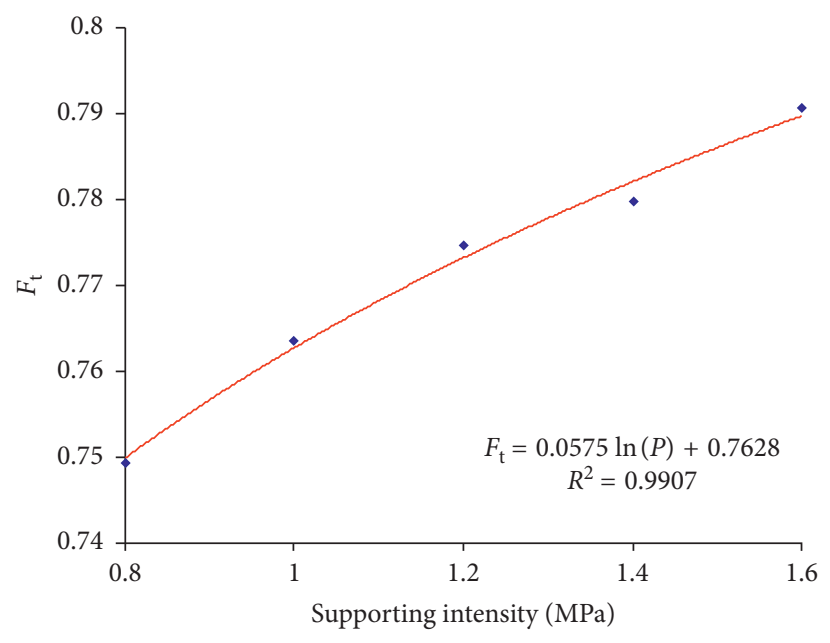

(e)

Figure 3: The fitting curves of each factor and $F_{\mathrm{t}}$.

where $[E]$ is the elastic matrix, $[\varepsilon]$ is the strain matrix, $[\Omega]$ is the damage matrix, $[I]$ is the unit matrix, $[\sigma]$ is the stress matrix, and $\left[\sigma^{*}\right]$ is the effective stress matrix.
The damage parameter $\Omega$ in the coal-rock obeyed the Weibull distribution, so the damage variable $D$ can be expressed as follows [20]: 


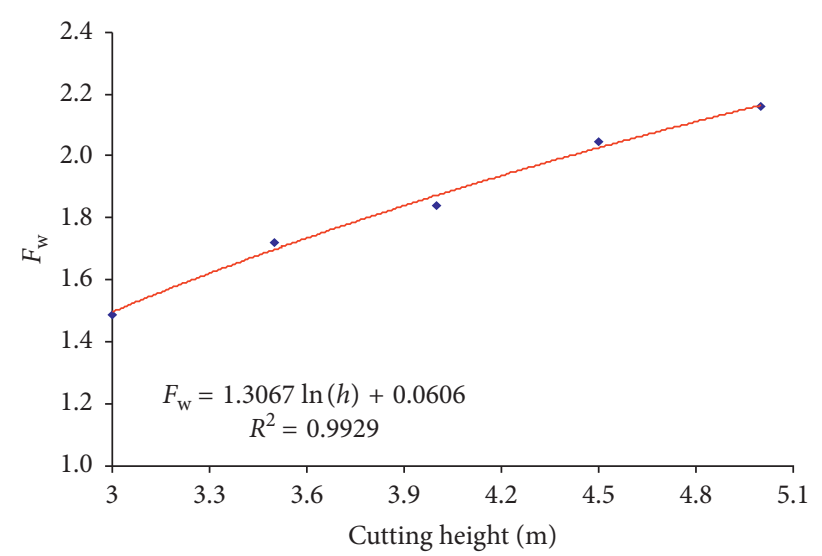

(a)

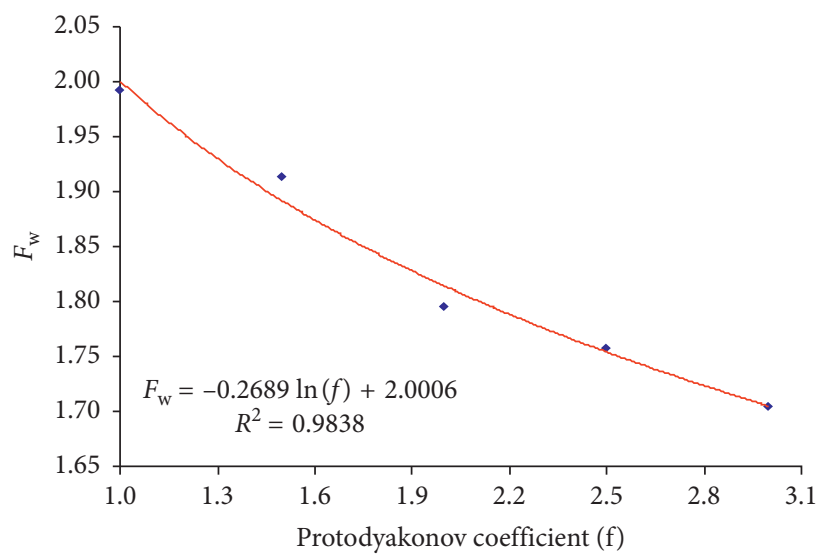

(c)

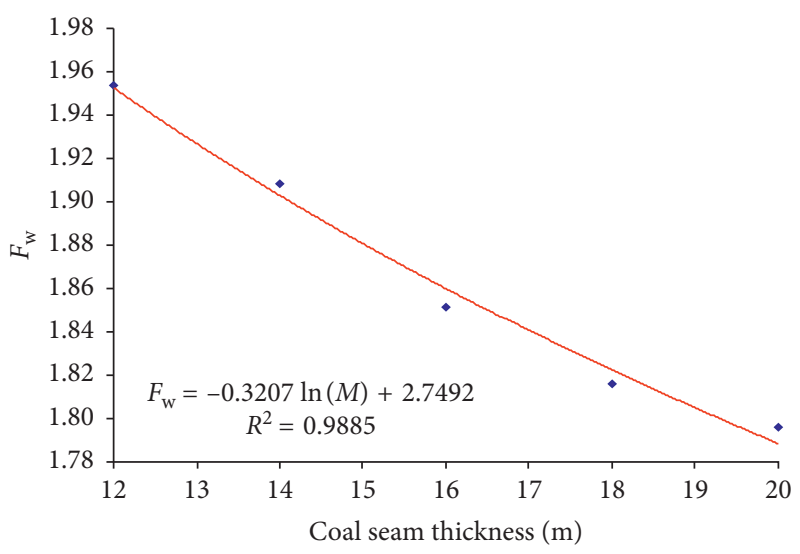

(b)

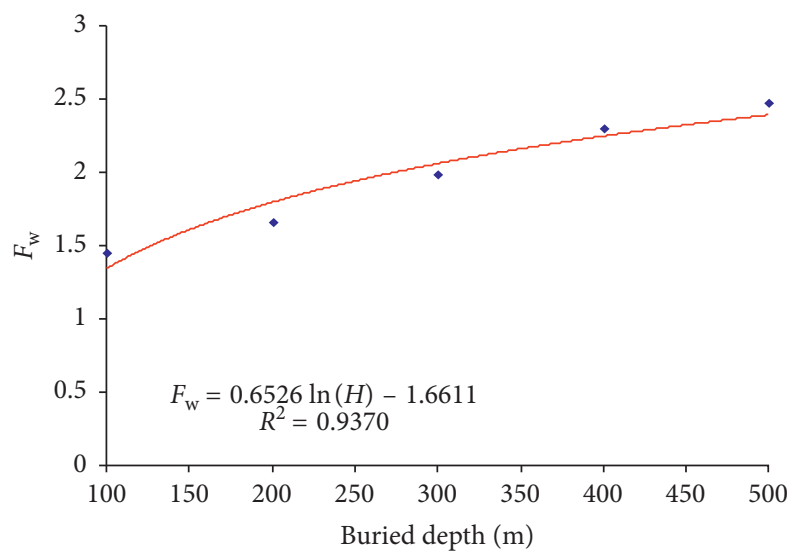

(d)

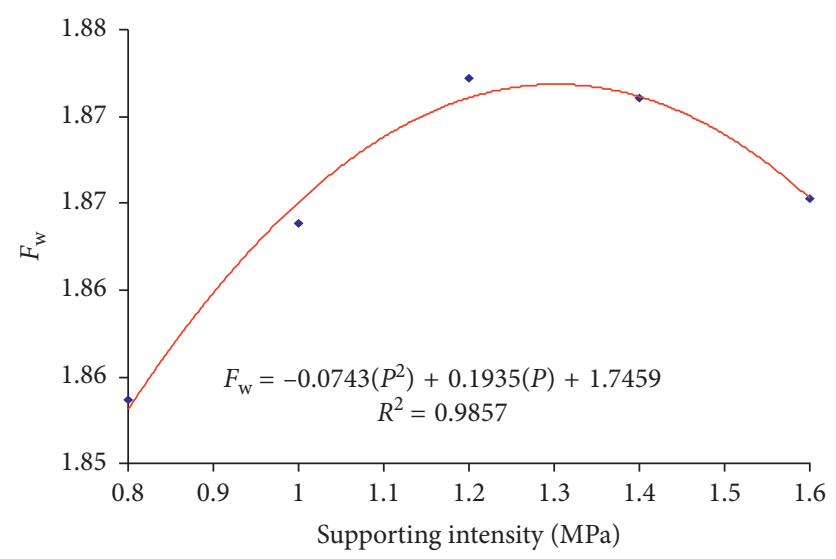

(e)

Figure 4: The fitting curves of each factor and $F_{\mathrm{w}}$.

$$
D=\int_{0}^{\varepsilon} \frac{m}{\varepsilon_{0}}\left(\frac{x}{\varepsilon_{0}}\right)^{m-1} \exp \left[-\left(\frac{x}{\varepsilon_{0}}\right)^{m}\right] \mathrm{d} x=1-\exp \left[-\left(\frac{\varepsilon}{\varepsilon_{0}}\right)^{m}\right] \text {, }
$$

where $m$ is the Weibull distribution scale, $\varepsilon_{0}$ is the Weibull distribution morphological parameter, and $\varepsilon$ is the strain of the microelement.

By establishing the rock statistical damage constitutive model (when the damage occurred), the rock damage strain under the uniaxial stress can be expressed as follows:

$$
\varepsilon=\frac{\sigma_{0}}{E}=\varepsilon_{1}-\frac{\sigma_{3}}{2 E},
$$

where $\sigma_{0}, \sigma_{3}, \varepsilon_{1}$, and $E$ are the uniaxial strength, the principal stress, the principal strain, and the elastic modulus, respectively.

The rock principal stresses obtained from equations (6)-(8) are as follows: 


$$
\sigma_{1}=2 \mu \sigma_{3}+E \varepsilon_{3}(1-D)=2 \mu \sigma_{3}+E \varepsilon_{1} \exp \left[-\left(\frac{\varepsilon_{1}-\sigma_{3} / 2 E}{\varepsilon_{0}}\right)^{m}\right]
$$

where $\mu=0.25$ is Poisson's ratio and $\varepsilon_{1}$ and $\varepsilon_{3}$ are the principal strain.

When not disturbed, the coal body was continuous, intact, and under the initial stress. After the coal body was mined, the stress balance of the coal wall was destroyed and redistributed; thus, the horizontal stress was reduced rapidly. The coal wall edge was the first to be damaged, and the crack spread deeper until the elasticity.

The cohesion and internal friction angles of the coal-rock interface were smaller than that of the coal body. Therefore, the fractured top coal could be regarded as the control object of the hydraulic support. Under the supporting pressure, the coal body in the elastic zone will be displaced toward the goaf, forming the limit equilibrium zone, as shown in Figure 5.

From the working face to the front of the coal wall, $0-x_{1}$ is the coal wall plastic failure area, where $0-x_{0}$ is the coal wall crushing area, $x_{1}-x_{2}$ is the coal wall elastic area, and the abutment pressure peak is the dividing line of the plastic area and the elastic area. According to the limit equilibrium theory, the stress $\sigma_{y}$ on the coal seam stratification in the limit equilibrium zone can be obtained as follows [20]:

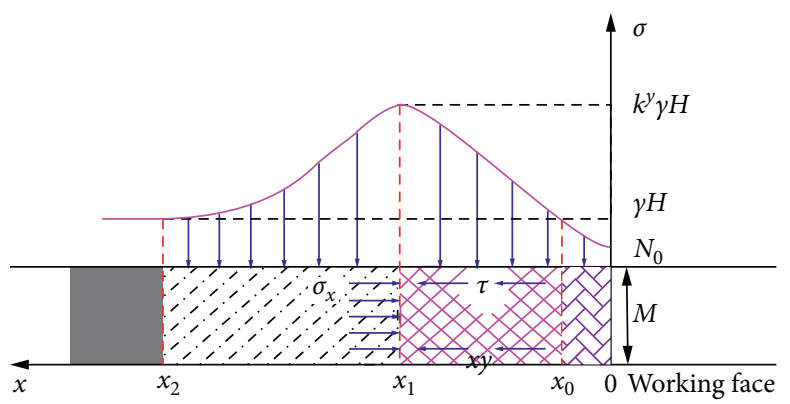

FIGURE 5: Distribution characteristics of elastic and plastic zones in coal wall.

$$
\sigma_{y}=\frac{c}{\tan \varphi}\left[\exp \left(\frac{2 \tan \varphi}{M \lambda} x\right)-1\right]
$$

where $\varphi$ is the internal friction angle of the coal-rock interface, $M$ is the cutting height, $x$ is the distance from the boundary of the balance zone to the coal wall, $\lambda$ is the side pressure coefficient, and $c$ is the cohesion of the coal-rock interface.

From equations (9) and (10), the cutting height of FMMTCCT is obtained as follows:

$$
M=\frac{2 \tan \varphi \cdot x}{\lambda \ln \left\{\left\{\left[\mu \sigma_{3} \exp -(1 / x)\right]+(E u / h) \exp \left[\left(-(u / h)-\left(\left(\sigma_{3} \exp -(1 / x)\right) / 2 E\right) / \varepsilon_{0}\right)^{m}\right]+c_{0} / \tan \varphi_{0}\right\} \times \tan \varphi / c\right\}} .
$$

Equation (11) demonstrates that the cutting height $M$ is inversely proportional to the confining pressure $\sigma_{3}$. The cutting height is proportional to the coal cohesion and internal friction angle. Once the coal cohesion and internal friction angle are fixed, the higher the cutting height, the more serious the rib spalling, especially on the FMCMLMH. Decreasing the mining height could ease the rib spalling, but the TCCP is poor, affecting the recovery rate.

3.2. Adaptability Analysis of the FMCMLMH. The top coal damaged by shearing was compressed and not easy to inbreak. Fully fractured top coal above the drawing opening, but not by shearing, was the key to its smooth release, which could guarantee the timely inbreak of top coal and high recovery rate. Among the 25 schemes of numerical simulation, 20 of them had a TCYFC more than 0.6 , and the top coal yielded failure zone above the support extended to the immediate roof. When the TCYFC was less than 0.6 , the top coal in certain range above the drawing opening did not fail, and the top-coal loss rate was high. Therefore, the TCYFC being 0.6 was the judgment index of whether the top coal was fully fractured.

The simulation showed that the greater the supporting intensity, the better the coal wall stability. However, this will result in a larger column cylinder diameter, indicating that the manufacturing cost would increase sharply. Additionally, the maximum supporting intensity of the FMMTCCT should not exceed 1.6 MPa, so it was determined as $P=$ 1.6 $\mathrm{MPa}$ in this study.

According to Figures 3 and 4, when the buried depth was $100-400 \mathrm{~m}$, the TCYFC and the CWYFC changed greatly. When the buried depth exceeded $400 \mathrm{~m}$, the two coefficients were basically stable. This reflected that the buried depth had a little effect on the coefficients. Therefore, a buried depth of $400 \mathrm{~m}$ was performed as a constant value for further analysis.

In order to ensure that the top coal fully inbreak, it must meet the following criterion:

$$
\begin{aligned}
F_{\mathrm{t}}= & 0.853994+0.13486 \ln h-0.14296 \ln M+0.2436 \ln f \\
& +0.0013581 \ln H+0.01546 \ln P \geq 0.6 .
\end{aligned}
$$

And it must be finished up as follows:

$0.13486 \ln h-0.14296 \ln M+0.2436 \ln f+0.2694 \geq 0$.

In the simulation of coal wall stability $(P=1.6 \mathrm{MPa}$, $H=400 \mathrm{~m}), 17$ of the 25 schemes had a CWYFC more than 1.5 , and the yield failure zone penetrated into the entire 


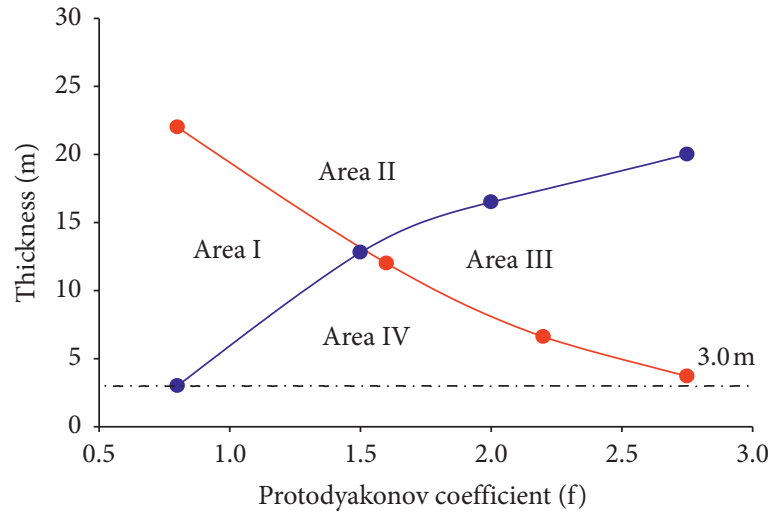

- Relationship between $F_{\mathrm{w}}$ and coal seam strength Relationship between $F_{\mathrm{t}}$ and coal seam strength

(a)

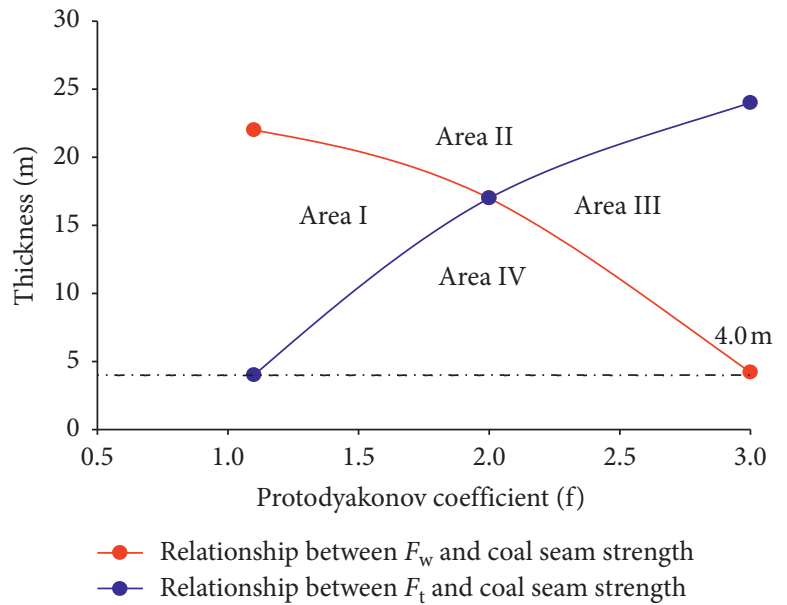

(c)

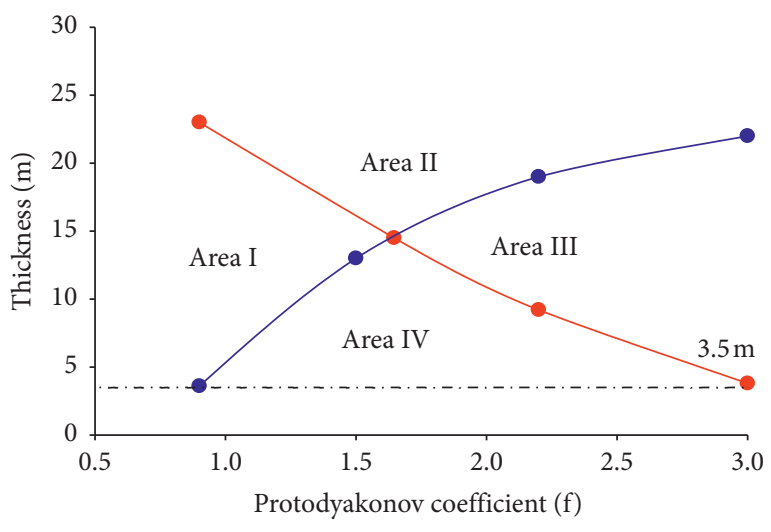

$\rightarrow-$ Relationship between $F_{\mathrm{w}}$ and coal seam strength Relationship between $F_{\mathrm{t}}$ and coal seam strength

(b)

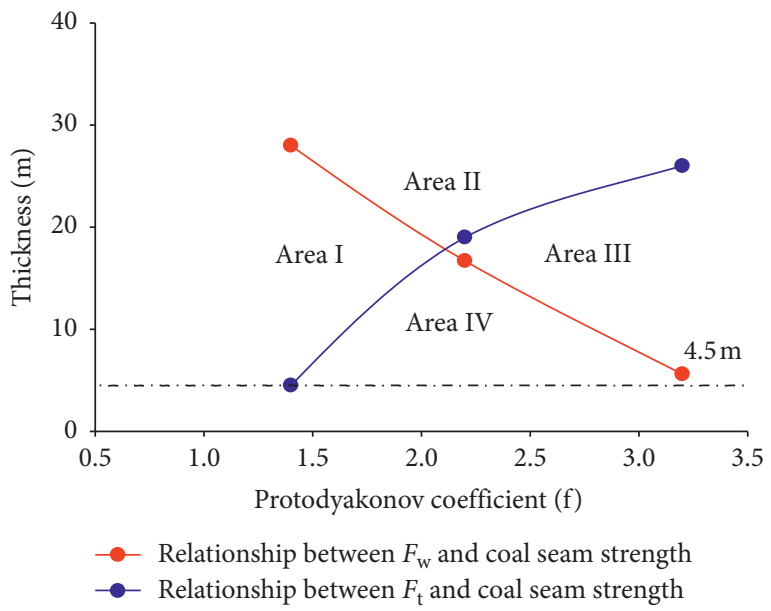

(d)

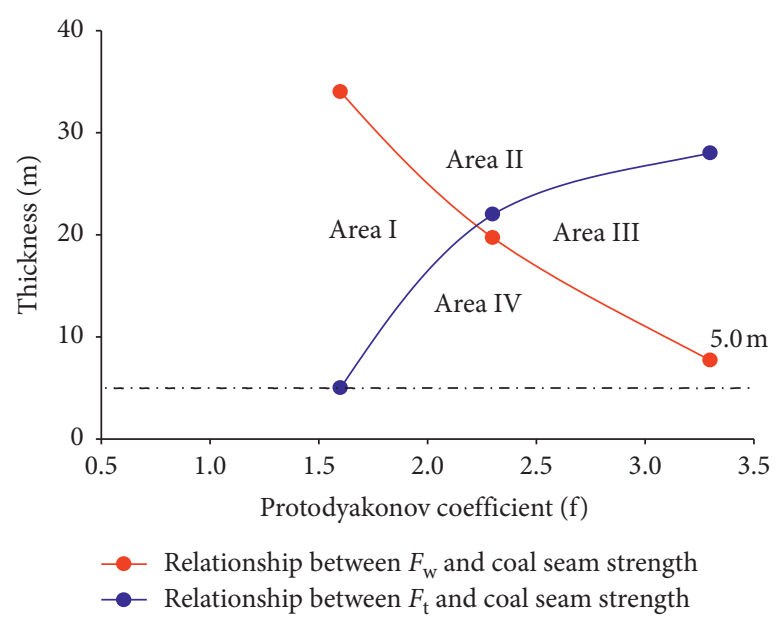

(e)

FIGURE 6: The interaction relationship between the coal seam strength and the top-coal thickness under different cutting heights.

height range, resulting in the complete coal wall fracture. The CWYFC being less than 1.5, the whole coal wall failed, but the failure depth was small, indicating that the coal wall still had a certain bearing capacity and was not completely instable. Therefore, the CWYFC being 1.5 could be be a judgment indicator of whether the coal wall was stable.

To realize the coal wall stability, the cutting height, the coal seam thickness, the Protodyakonov coefficient, and the buried depth must meet the following condition: 
TABLE 2: Coal seam strength and thickness under different cutting heights.

\begin{tabular}{lcc}
\hline Cutting height $(\mathrm{m})$ & Requirements for the coal seam strength $(\mathrm{MPa})$ & Requirements for the coal seam thickness $(\mathrm{m})$ \\
\hline 3.0 & $>0.8$ & $<13$ \\
3.5 & $>0.9$ & $<15$ \\
4.0 & $>1.1$ & $<17$ \\
4.5 & $>1.4$ & $<19$ \\
5.0 & $>1.6$ & $<22$ \\
\hline
\end{tabular}

$$
\begin{aligned}
F_{\mathrm{w}}= & 1.58574+0.26292 \ln h-0.13026 \ln M-0.326034 \ln f \\
& +0.00248 \ln H-0.1268 \ln P \leq 1.5 .
\end{aligned}
$$

And it must comply with the following constraint:

$$
0.26292 \ln h-0.13026 \ln M-0.326034 \ln f+0.3299<0 \text {. }
$$

To ensure the coal wall stability and high coal recovery rate of FMCMLMH, the cutting height, coal seam thickness, and the Protodyakonov coefficient must satisfy both inequalities expressed in equations (13) and (15). Taking the cutting heights $3 \mathrm{~m}, 3.5 \mathrm{~m}, 4 \mathrm{~m}, 4.5 \mathrm{~m}$, and $5 \mathrm{~m}$, respectively, and the relationship between the coal seam thickness and the Protodyakonov coefficient under different cutting heights could be obtained as shown in Figure 6 .

Based on the comparative analysis of coal seam thickness and hardness, the two curves and the horizontal line of cutting height could divide the coal seam into four areas according to the TCCP and the coal wall stability: (i) Area I with good TCCP and the instable coal wall; (ii) Area II with poor TCCP and instable coal wall; (iii) Area III with poor TCCP and stable coal wall; and (iv) Area IV suitable for FMCMLMH.

The top-coal thickness and coal seam strength could satisfy the FMMTCCT. The vertical coordinate corresponding to the intersection point of the two curves is the upper limit of top-coal thickness. The intersection points of the two curves and the horizontal line are the upper and lower limits of the coal seam strength, respectively. The topcoal thickness at this time was 0 , which was the requirement for coal seam strength of FMCMLMH.

As seen from the Figure 6, the coal wall stability increases with the strength increasing when the latter is small, and the maximum mining height is continuously increased. When the coal seam strength exceeds a certain value (Table 2), the maximum mining height decreases due to the top-coal recovery rate [21]. This indicates that if the top coal is soft, FMMTCCT can be adopted mainly on the coal wall stability for hard coal, and it depends mainly on the TCCP.

Table 2 shows the requirements for strength and thickness under different cutting heights. Increasing the cutting height could significantly increase the maximum mining height of the FMCMLMH, but the limited minimum strength is correspondingly increased. When the cutting height is more than $3.5 \mathrm{~m}$, the Protodyakonov coefficient must be larger than 0.9 to ensure the coal wall stability.

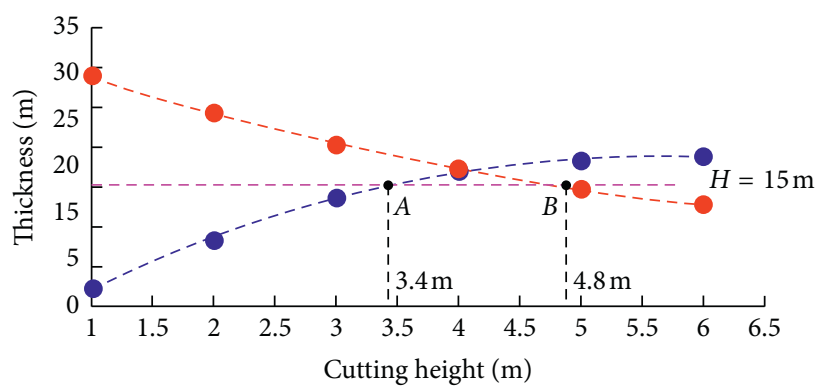

Figure 7: Relationship between coal seam thickness and cutting height $(f=2.2 ; P=1.45 \mathrm{MPa} ; H=360 \mathrm{~m})$.

\subsection{Field Application Effect Analysis of FMCMLMH}

3.3.1. Analysis of Coal Wall Rib Spalling. $\varphi=31^{\circ}$, $c=6.2 \mathrm{MPa}, m=3.0$, and $\varepsilon_{0}=0.01$ of the 23103 working face were substituted into the formula for the mining height $M=3.5-4.2 \mathrm{~m}$ with the rib spalling depth between $230 \mathrm{~mm}$ and $280 \mathrm{~mm}$. For the coal wall stability, when the mining height was $4.0 \mathrm{~m}$, the rib spalling was in a controllable range.

\subsubsection{Determination of Reasonable Cutting-Caving Ratio.} The Protodyakonov coefficient $f=2.2$ was substituted into the inequality of coal wall stability and top-coal recovery rate, and then the relationship curve between the coal seam thickness and the cutting height was obtained. As demonstrated in Figure 7, the abscissa corresponding to the points $\mathrm{A}$ and $\mathrm{B}$ are the highest and lowest cutting height, which are $3.4 \mathrm{~m}$ and $4.8 \mathrm{~m}$, respectively. When the cutting height was less than $3.4 \mathrm{~m}$, the top coal could not fully inbreak and the recovery rate was low. When the cutting height is greater than $4.8 \mathrm{~m}$, it is difficult to achieve the coal wall stability control [22].

According to the above analysis, it was feasible to apply the FMCMLMH to the first working face in Xiegou Coal Mine. The optimal mining height was obtained as $4.0 \mathrm{~m}$, and the reasonable cutting-caving ratio was determined to be 1 : 2.75. The results indicated that great success was achieved and a recovery rate of $85 \%$ was reached in the field application.

\section{Conclusions}

In this study, theoretical calculation, numerical simulation, and engineering application were implemented to optimize the reasonable cutting-caving ratio of the FMCMLMH in extremely thick coal seam under the restriction of different effective factors. Based on the results obtained with the present study, the following items can be drawn: 
(i) The reasonable mining height mechanical model of extremely thick coal seam was established under the constraints of the coal wall damage and the TCCP, and the calculation formula for the reasonable mining height of FMCMLMH was derived.

(ii) $F_{\mathrm{t}}$ and $F_{\mathrm{w}}$ were defined to quantitatively describe the TCCP and the coal wall stability. According to the orthogonal test and numerical simulation, the buried depth and Protodyakonov coefficient were the main factors affecting the TCYFC, whilst the buried depth and the mining height were the main factors affecting the CWYFC.

(iii) The inequality relationship between the coal wall stability and the top-coal recovery rate of the FMCMLMH was obtained. The coal wall was divided into four areas, and Area IV was suitable for FMCMLMH mining.

(iv) With stable coal wall and the good TCCP, a cutting height of $4.0 \mathrm{~m}$, and a cutting-caving ratio of $1: 2.75$, the recovery rate reached $85 \%$, which met the FMCMLMH requirements of Xiegou Coal Mine.

\section{Data Availability}

The data used to support the findings of this study are available from the corresponding author upon request.

\section{Conflicts of Interest}

The authors declare that there are no conflicts of interest including any financial, personal, or other relationships with other people or organizations.

\section{Acknowledgments}

This paper was supported by the China National Key R\&D Program during the 13th Five-Year Plan Period (no. 2017YFC0603003), Scientific and Technological Innovation Programs of Higher Education Institutions in Shanxi Province (STIP) (no. 2019L0347), and the Natural Science Foundation of China (no. 51704204 and 51974194), which are greatly appreciated by the authors.

\section{References}

[1] C. X. Ji, Y. K. Yang, X. Y. Guo, T. H. Kang, and Z. F. Guo, "Influence law of interbedded strata and their collapse on the mining of extremely thick coal seam under goaf," Advances in Civil Engineering, vol. 2019, Article ID 5171873, 11 pages, 2019.

[2] Z.-1. Li, X.-q. He, L.-m. Dou, D.-z. Song, and G.-f. Wang, "Numerical investigation of load shedding and rockburst reduction effects of top-coal caving mining in thick coal seams," International Journal of Rock Mechanics and Mining Sciences, vol. 110, pp. 266-278, 2018.

[3] D. J. Zhu, Z. H. Chen, W. S. Du, L. F. Zhang, and Z. H. Zhou, "Caving mechanisms of loose top-coal in longwall top-coal caving mining based on stochastic medium theory," Arabian Journal of Geosciences, vol. 11, no. 20, p. 621, 2018.
[4] H. J. Li, Q. T. Chen, Z. Y. Shu, L. Li, and Y. C. Zhang, "On prevention and mechanism of bed separation water inrush for thick coal seams: a case study in China," Environmental Earth Sciences, vol. 77, no. 22, p. 759, 2018.

[5] Z. Wang, J. Wang, and S. Yang, "An ultrasonic-based method for longwall top-coal cavability assessment," International Journal of Rock Mechanics and Mining Sciences, vol. 112, pp. 209-225, 2018.

[6] J.-W. Zhang, J.-C. Wang, W.-J. Wei, Y. Chen, and Z.-Y. Song, "Experimental and numerical investigation on coal drawing from thick steep seam with longwall top coal caving mining," Arabian Journal of Geosciences, vol. 11, no. 5, p. 96, 2018.

[7] D. S. Yantek, L. Yan, N. W. Damiano, M. A. Reyes, and J. R. Srednicki, "A test method for evaluating the thermal environment of underground coal mine refuge alternatives," International Journal of Mining Science and Technology, vol. 29, no. 3, pp. 343-355, 2019.

[8] B. Huang, Q. Cheng, X. Zhao, and C. Kang, "Hydraulic fracturing of hard top coal and roof for controlling gas during the initial mining stages in longwall top coal caving: a case study," Journal of Geophysics and Engineering, vol. 15, no. 6, pp. 2492-2506, 2018.

[9] Q. S. Bai and S. H. Tu, "A general review on longwall mininginduced fractures in near-face regions," Geofluids, vol. 2019, Article ID 3089292, 22 pages, 2019.

[10] Y. P. Liang, L. Li, X. L. Li et al., "Study on roof-coal caving characteristics with complicated structure by fully mechanized caving mining," Shock and Vibration, vol. 2019, Article ID 6519213, 20 pages, 2019.

[11] Q. X. Huang, M. Y. Zhao, Y. L. Tan, and K. J. Huang, "Study of roof double key strata structure and support resistance of shallow coal seams group mining," Journal of China University of Mining \& Technology, vol. 48, no. 1, pp. 71-77, 2019.

[12] Y. Chen, S. Ma, and Y. Yu, "Stability control of underground roadways subjected to stresses caused by extraction of a 10-m-thick coal seam: a case study," Rock Mechanics and Rock Engineering, vol. 50, no. 9, pp. 25112520, 2017.

[13] C. Liu, H. Li, and H. Mitri, "Effect of strata conditions on shield pressure and surface subsidence at a longwall top coal caving working face," Rock Mechanics and Rock Engineering, vol. 52, no. 5, pp. 1523-1537, 2019.

[14] T. D. Le, C. Zhang, J. Oh, R. Mitra, and B. Hebblewhite, “A new cavability assessment for Longwall Top Coal Caving from discontinuum numerical analysis," International Journal of Rock Mechanics and Mining Sciences, vol. 115, pp. 11-20, 2019.

[15] F. Wang, J. Xu, and J. Xie, "Effects of arch structure in unconsolidated layers on fracture and failure of overlying strata," International Journal of Rock Mechanics and Mining Sciences, vol. 114, pp. 141-152, 2019.

[16] X. G. Ma, M. C. He, X. Z. Li, E. Y. Li, C. W. Hu, and R. Gao, "Deformation mechanism and control measures of overlying strata with gob-side entry retaining formed by roof cutting and pressure releasing," Journal of China University of Mining \& Technology, vol. 48, no. 3, pp. 474-483, 2019.

[17] J. H. Liu, F. X. Jiang, and S. T. Zhu, "Study of dynamic and static abutment pressure around longwall face and its application," Chinese Journal of Rock Mechanics and Engineering, vol. 34, pp. 1815-1827, 2015.

[18] Y. Zhao, S. Wang, Z. Zou, L. Ge, and F. Cui, "Instability characteristics of the cracked roof rock beam under shallow mining conditions," International Journal of Mining Science and Technology, vol. 28, no. 3, pp. 437-444, 2018. 
[19] Z. N. Gao, X. R. Meng, and X. Q. Wang, "Prediction of regime change in jian li reach of Yangtze river during the early operation stage of three Gorges project," Journal of Yangtze River Scientific Research Institute, vol. 28, no. 5, pp. 31-34, 2011, in Chinese.

[20] B. X. Liu, J. L. Huang, Z. Y. Wang, and L. Liu, "Study on damage evolution and acoustic emission character of coalrock under uniaxial compression," Chinese Journal of Rock Mechanics and Engineering, vol. 28, no. S1, pp. 3234-3238, 2009, in Chinese.

[21] X. Wang and M. Cai, "A comprehensive parametric study of grain-based models for rock failure process simulation," International Journal of Rock Mechanics and Mining Sciences, vol. 115, pp. 60-76, 2019.

[22] Q. Sun, J. Zhang, Q. Zhang, W. Yin, and D. Germain, “A protective seam with nearly whole rock mining technology for controlling coal and gas outburst hazards: a case study," Natural Hazards, vol. 84, no. 3, pp. 1793-1806, 2016. 


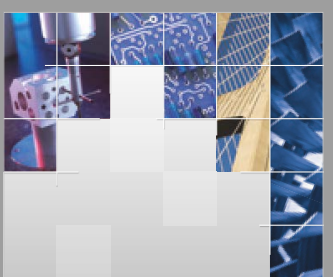

\section{Enfincering}
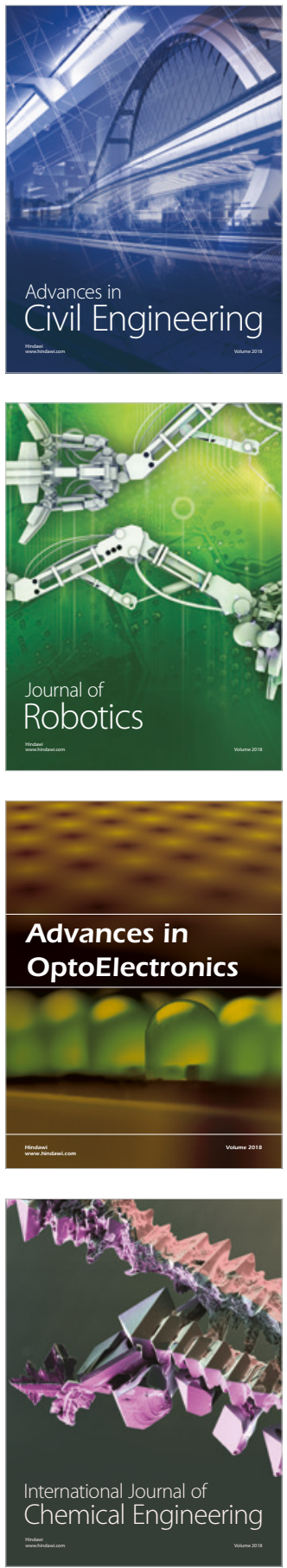

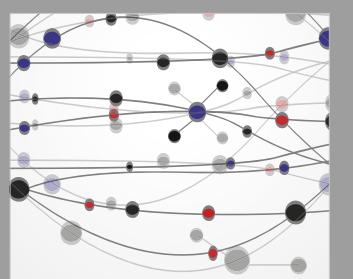

\section{Rotating \\ Machinery}

The Scientific World Journal

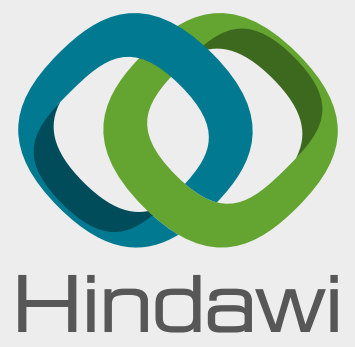

Submit your manuscripts at

www.hindawi.com
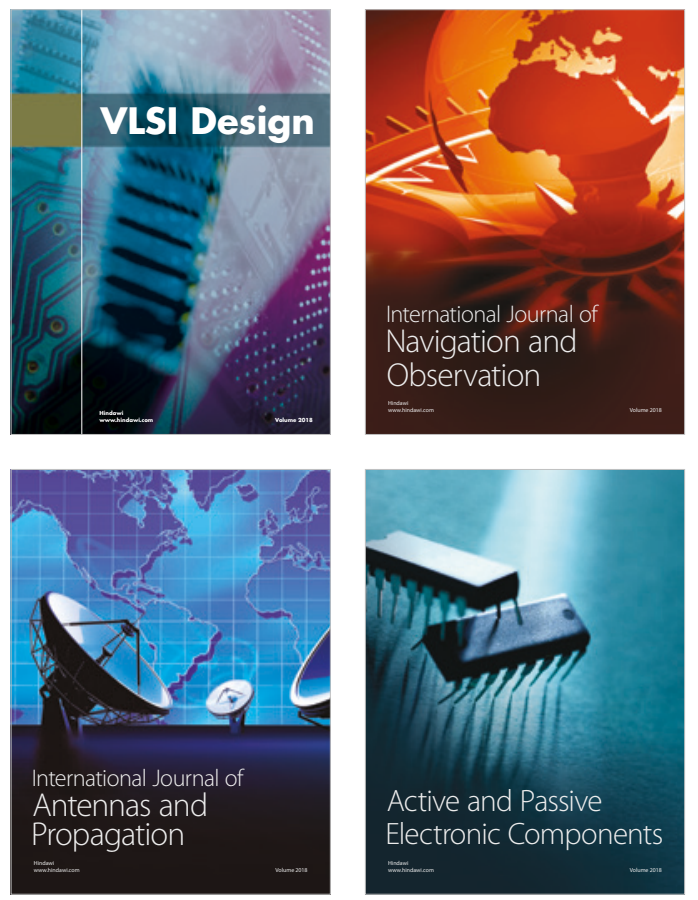
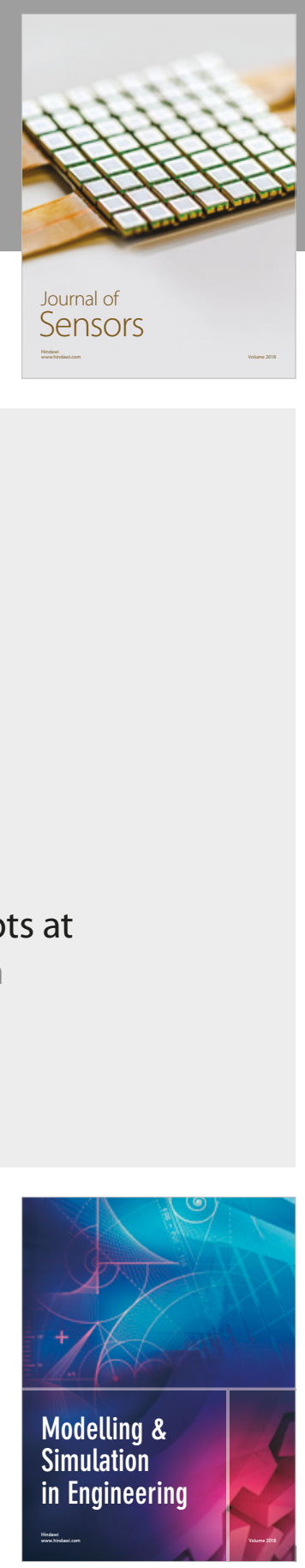

\section{Advances \\ Multimedia}
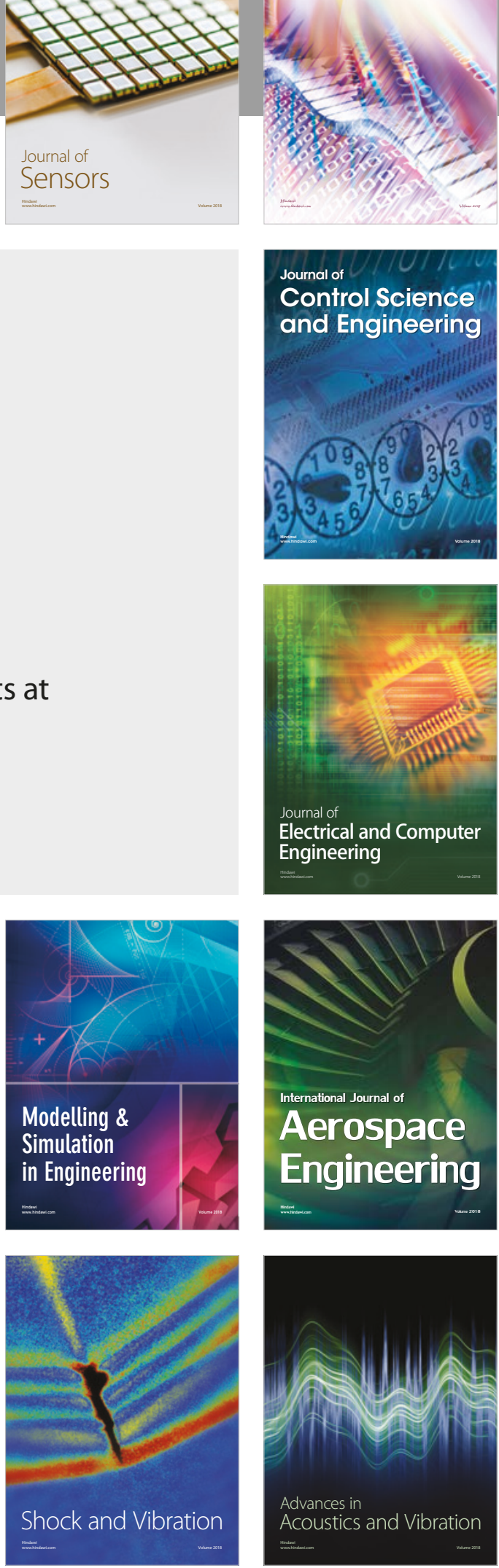